\title{
Escuta clínica: Experiência de uma mãe enlutada em tempos de Covid-19
}

\author{
Ana Maria Lopez Calvo de Feijoo \\ Departamento de Psicologia Clínica, Universidade do Estado do Rio de Janeiro (Uerj)
}

Submissão: 24 ago. 2020.

Aceite: 18 maio 2021.

\section{Notas da autora}

Ana Maria L. C. de Feijoo (D) https://orcid.org/0ooo-0002-3064-3635

Correspondências referentes a este artigo devem ser enviadas para Ana Maria Lopez Calvo de Feijoo, Rua Barão de Piracinunga, 62, Tijuca, Rio de Janeiro, RJ, Brasil. CEP 20520-170. E-mail: ana.maria.feijoo@gmail.com 


\title{
Resumo
}

O objetivo deste artigo é apresentar a dinâmica de uma situação clínica com uma mãe enlutada pela morte de seu filho vitimado pela Covid-19, por meio de um estudo teórico-clínico pautado no método fenomenológico. Em uma perspectiva clínica com bases fenomenológico-existenciais, mostraremos uma atuação psicoterapêutica em que o luto é compreendido para além dos critérios posicionados pelo DSM-5. Nas pesquisas fenomenológicas acerca do luto materno, o luto é compreendido como algo da ordem do incontornável e do imensurável. É com essa compreensão do afeto dos enlutados que apresentaremos a dinâmica de uma atuação clínica de uma mulher de 50 anos atendida pelo Serviço de Psicologia Aplicada de uma universidade pública. Destacamos que o silêncio do psicoterapeuta, durante o atendimento da mãe enlutada, favoreceu que ela se sentisse compreendida em sua dor.

Palavras-chave: Covid-19, luto, clínica psicológica, silêncio, fenomenologia existencial

\section{CLINICAL LISTENING: EXPERIENCE OF A GRIEVING MOTHER IN TIMES OF COVID-19}

\begin{abstract}
The aim of this article is to present the dynamics of a clinical situation with a mother bereaved by the death of her child victimized by Covid-19, through a theoretical-clinical study based on the phenomenological method. From the perspective and bases of the clinical phenomenological-existential, we will show a psychotherapeutic action in which grief is understood beyond the criteria positioned by the DSM-5. In phenomenological research on maternal mourning, mourning is understood as something of the order of the inescapable and the immeasurable. It is with this understanding of the affection of the bereaved that we will present the dynamics of a clinical performance of a 50-year-old woman attended by the Applied Psychology Service of a public university. We emphasize that the silence of the psychotherapist, during the care of the bereaved mother, favored that the mother felt understood in her pain.
\end{abstract}

Keywords: Covid-19, grief, psychological clinic, silence, phenomenology existential

\section{ESCUCHA CLÍNICA: EXPERIENCIA DE UNA MADRE DOLIENTE EN TIEMPOS DEL COVID-19}

\section{Resumen}

El objetivo de este artículo es presentar la dinámica de una situación clínica con una madre afligida por la muerte de su hijo víctima de Covid-19, a través de un estudio teórico-clínico basado en el método fenomenológico. Desde una perspectiva clínica con bases fenomenológicas-existenciales, mostraremos una acción psicoterapéutica en la que el dolor se entiende más allá de los criterios posicionados por el 
DSM-5. En la investigación fenomenológica sobre el duelo materno, el luto se entiende como algo del orden de lo ineludible y lo inconmensurable. Es con esta comprensión del afecto de los afligidos que presentaremos la dinámica de un desempeño clínico de una mujer de 50 años a la que asistió el Servicio de Psicología Aplicada de una universidad pública. Hacemos hincapié en que el silencio de la psicoterapeuta, durante el cuidado de la afligida madre, favoreció que la madre se sintiera comprendida en su dolor.

Palabras clave: Covid-19, duelo, psicología clínica, silencio, fenomenología existencial 
A pandemia da coronavirus disease 2019 (Covid-19) é tratada por medidas preventivas como o afastamento social e a higienização das mãos. Manuais indicam os procedimentos e comportamentos adaptativos àqueles que sofrem pelo isolamento, pelo medo da contaminação e pela perda de um ente próximo. O que queremos propor, neste artigo, é uma atuação clínica, em uma perspectiva fenomenológico-existencial, destinada a uma mãe enlutada, que muitas vezes sofre pela solidão e pela lembrança que insiste em trazer o momento da morte de seu ente próximo.

A perspectiva fenomenológico-existencial em psicoterapia surge na década de 1950 e tem como principal representante Medard Boss. Esse estudioso denominou sua perspectiva clínica de daseinsanálise, mas algumas vezes referia-se a ela como fenomenologia existencial, denominação que foi amplamente utilizada pelos estudiosos do tema (Boss, 1988). Importa destacar que esse modo de pensar a clínica psicológica se manteve e continua a se manter em diálogo com o filósofo Martin Heidegger e que apenas nos últimos dez anos vem ganhando espaço em território brasileiro

Sabemos que Freud (1915/1975), Bowlby (1980), Kübler-Ross (1998), entre outros estudiosos, tematizaram o luto, bem como apontaram para estratégias clínicas para tratar os enlutados. Embora não haja dúvida das ricas contribuições desses estudiosos acerca do tema, esses posicionamentos mantêm a ideia de que o luto consiste em uma energia libidinal que precisa ser revista, é algo que se apresenta em diferentes fases ou ainda que deve ser elaborado ou ressignificado. Na perspectiva fenomenológico-existencial, o luto é compreendido como uma experiência humana e, portanto, não é passível de sistematização, bem como não é tomado como patológico, na maioria dos casos.

Boss encaminhou uma proposta para a prática clínica na daseinsanálise dirigida a vários temas, no entanto, a tematização do luto, bem como a proposta de uma clínica psicológica na perspectiva fenomenológica com o luto, aparece apenas em publicações a partir de 1991, quando Brice (1991), psicoterapeuta especializado em luto, publica um artigo sobre o luto materno. Esse artigo trata dos resultados de uma pesquisa fenomenológica realizada por Brice (1991) que conclui que o luto materno é para sempre.

Kovács (1992) e Comte-Sponville (1997), também com ênfase na fenomenologia, publicam artigos sobre o tema e chegam ambos à mesma conclusão: o sofrimento do enlutado aparece a cada vez que este não aceita a perda. Todo o trabalho clínico acontece no sentido de que o enlutado possa aceitar a sua situação. Esslinger (2008) define o luto como o vínculo que se rompe de forma irreversível, ou seja, reconhece-o como algo da ordem da existência e, por isso, não deve ser acompanhado como uma doença a ser tratada por medicamentos, porém diz esse estudioso que, afinal, o que importa é a experiência do luto. Freitas (2013, 2018), imbuída da perspectiva fenomenológica, encaminha uma proposta compreensiva da vivência do luto e refere-se à experiência como a de um eu sem tu. A autora ainda defende que o espaço clí- 
nico sustenta a possibilidade de ressignificação do luto na medida em que abre outras possibilidades de lida com a dor. Azevedo e Pereira (2013), no artigo intitulado "O luto na clínica psicológica: um olhar fenomenológico", chegam a uma conclusão muito esclarecedora: ao retirarem esse momento de vida da categoria de uma doença ou dividindo-o em fases, apontam que o luto é caminho para uma despedida.

Por fim, Feijoo (2021) refere-se ao luto dos pais que perderam seus filhos por suicídio e, indo ao encontro das teses de Brice, defende que o luto não é passível de ressignificação nem de elaboração. Essa autora, afinada à proposta de uma psicologia fenomenológico-existencial, compreende que uma psicologia inspirada na ontologia fundamental de Heidegger não pressupõe consciência nem psiquismo e, portanto, não cabe falar em elaboração nem em ressignificado. Feijoo (2021) defende ainda que o trabalho clínico com o luto deve se encaminhar por uma perspectiva da saudade. A técnica, no sentido de um modo de fazer, consiste em acompanhar por meio da escuta clínica, compreensivamente, a dor do enlutado, para dessa forma sustentar a possibilidade de que o ressentimento, a solidão e a tristeza profunda deem lugar à saudade. Saudade que, ao mesmo tempo que traz a tristeza da lembrança, traz também a alegria do ter o que recordar.

A proposta deste texto é apresentar um encontro psicoterapêutico, que se deu on-line por nos encontrarmos em período de isolamento, com uma mulher enlutada pela morte de seu filho por Covid-19. Esse atendimento faz parte de uma pesquisa-ação intitulada Morte, luto e psicoterapia em tempos de Covid-19, cujo objetivo consiste em aprimorar o atendimento psicológico em situações de luto. Denominamos a investigação que realizamos de pesquisa-ação porque, ao mesmo tempo que fazemos o levantamento de dados, atuamos clinicamente nas situações de luto, pedimos que os participantes assinem o Termo de Consentimento Livre Esclarecido e trabalhamos na análise dos conteúdos presentes nos relatos.

O encontro psicoterapêutico com pessoas enlutadas, nessa pesquisa-ação, ocorre em uma tentativa de não negar a dor ou encontrar um subterfúgio para ela. Ao contrário, toda a atuação acontece de modo a confirmarmos a dor do outro, compreendendo e aguardando o que pode aparecer como consequência da dor. Tentamos, em nossa tarefa clínica, acompanhar algo que o enlutado já sabe pela própria experiência, na qual ele vê, sente e pensa a dor como algo da qual ele não pode se esquivar - aliás, quanto mais tenta, mais dói, uma vez que se soma à dor do luto, a dor de esquivar-se da dor. Por isso, cabe ao psicólogo estar próximo ao enlutado, pacientemente, aguardando seu pensar, em voz alta, ou seja, aguardando o que ele tem a dizer, sem precisar atuar como se a dor não existisse.

Em pesquisas anteriores (Brice, 1991; Franqueira, 2013) com pais e mães enlutados, constatamos que o psicólogo acompanhou o que o enlutado tinha a dizer-lhe e ocorreu que os pais e as mães acabavam por romper os laços da ilusão (Feijoo, 2010), ou seja, acabavam 
aceitando o fato de que seus filhos não eram imortais. Por fim, pai e mãe apropriavam-se da conclusão de que a dor é inevitável.

Brice (1991) nos mostra como a dor do luto aparece nos relatos das mães enlutadas. As mães entrevistadas pelo pesquisador referiam-se ao fato de que não aceitavam que seus projetos de continuar com seus filhos ao seu lado fossem interrompidos. Em outras situações, como nos mostra Franqueira (2013), pai e mãe eram tomados por ressentimento, indignação e frustração, e falavam de tudo isso em meio à lamentação.

Pessoas enlutadas, frequentemente, falam da falta, culpa, impotência, saudade, amputação e vulnerabilidade. Cabe-nos, então, sustentar o espaço da dor para que essa possa se mostrar em toda sua potência. E, assim, o enlutado, ao se perceber compreendido, possa dispor de um espaço para compartilhar o seu luto. A relação psicoterapêutica, em uma perspectiva fenomenológico-existencial, sustenta o surgimento de outras possibilidades que se fazem na escuta e obediência à vida. Escuta que quer dizer cuidar do que se ouve, ou seja, obedecer. E, ainda, obediência, tal como posicionada por Kierkegaard (1848/2010), refere-se à postura daquele que sabe que vida comporta dor e alegria e que a luta para rejeitar a dor é desespero.

No espaço clínico, na perspectiva fenomenológico-existencial, o dizer do clínico é um exercício do despertar daquilo em que os pais se encontravam adormecidos, por estarem habituados com a ideia da morte como um ainda não, como sendo somente dos outros, algo do impessoal, passível de controle e adiamento. O querer dos pais se mostra em uma vontade que se enxerga soberana, sem entrega, sem escuta na obediência. É preciso evocar a experiência da escuta, da entrega ao seu destino. Tudo isso por meio da interpretação, que, na perspectiva fenomenológico-existencial, é a arte do bem perguntar (Feijoo, 2020). A arte do bem perguntar consiste em que o psicólogo clínico acompanhe o outro em seu relato de modo a poder sustentar, por meio ao silêncio, a clarificação do relato do paciente e das questões que visem a exemplificações das situações anunciadas. Na perspectiva fenomenológico-existencial, o psicólogo não interpreta aquilo que o paciente diz por meio de teorias. Ele apenas acompanha o relato ao modo do que denominamos a arte do bem perguntar. Nisso consiste a nossa técnica.

Defendemos a tese de que aquilo que nos chega aos consultórios de psicologia, na maioria das vezes, é o sofrimento pela não aceitação daquilo que de algum modo macula uma determinada existência. Ainda, na maioria das vezes, aquele que procura a psicoterapia quer a saída da dor. E é justamente querer sair da dor, da finitude, do incontornável e não poder sair dessas situações pelas próprias forças o que constitui o sofrimento.

Partimos da máxima que a dor da dor - sofrimento - (Fogel, 2010) é justamente aquilo que cabe ao psicólogo trabalhar, de modo que o homem afinal saiba que a dor é inevi- 
tável; a luta insana de escapar da dor é sofrimento, que só finaliza quando se para de lutar e se aceita que vida e dor são inseparáveis.

A seguir, apresentamos um encontro clínico em que a mãe traz uma dor dilacerante perante a morte de seu filho vitimado pela Covid-19. Nesta oportunidade, mostraremos como se deu o primeiro encontro, destacando aquilo que na dor do luto se agrava ante o fato de ter sido vítima da pandemia. É importante ressaltar que, por se tratar de um primeiro encontro, em que a mãe está totalmente tomada pela dor da perda de seu filho, o psicoterapeuta mantém-se, o máximo possível, em um acolhimento que privilegia a escuta acolhedora - que consiste em acolher o outro em sua dor sem a necessidade de nenhuma intervenção mais ousada - e, por isso, permanece quase que totalmente no silêncio. Podemos pensar, já que ele, o psicólogo, se mantém no silêncio, qual é a utilidade da psicoterapia? O enlutado não poderia ter esse desabafo com qualquer pessoa? Mostraremos que esse silêncio se dá em um aguardar que o outro em sua dor possa expressá-la com liberdade. O psicoterapeuta não o apressa, deixando que o enlutado possa dar outro sentido à sua experiência.

Por fim, o luto e a psicoterapia, em tempos de Covid-19, que apresentamos aqui representaram uma tentativa de mostrar um modo específico, para além das categorias da ciência, de pensar a morte, o luto e a prática clínica. Com a apropriação da morte como destino de todos os homens, entendendo as pandemias como algo com que a humanidade tem sempre que se confrontar, e seu consequente luto como uma dor inalienável, o psicólogo clínico pauta-se em um modo de pensar que privilegia a existência, que sabe, como quem experimenta a vida, que é assim que a vida é.

\section{Método}

O método empírico-fenomenológico de pesquisa em psicologia foi desenvolvido pela Duquesne University, em que Amedeo Giorgi é uma grande referência. Sousa e Giorgi (2010) apresentam as especificidades desse método, herdado da fenomenologia de Husserl, que, segundo eles, consiste, primeiramente, na capacidade de exercitar a atitude fenomenológica, ou seja, suspender todos os posicionamentos ontológicos (Epoché). Trata-se da eliminação de todas as perspectivas empíricas e idealistas. A suspensão é a radicalização da redução. Husserl (2000) diz que todo ver fenomenológico requer do pesquisador uma atitude antinatural, o que significa ver as coisas sem tomá-las como naturalmente dadas, ou seja, colocando entre parênteses as verdades postas pelo senso comum ou pela ciência. Na redução fenomenológica, compreende-se que o lembrar requer o objeto específico lembrado, assim como amar requer o objeto amado, do mesmo modo o pensar e o querer. Quando se está preso à perspectiva da atitude natural, não se consegue ver nenhuma especificidade do objeto em seu fluxo espacial e temporal, e, desse modo, o objeto é simplesmente a presença fática, que, no final das contas, é o que determina o ser das coisas, sejam elas de uma ordem exterior ou interior. 
A variação imaginativa, segundo momento da investigação fenomenológica, consiste em encontrar a essência do fenômeno que interessa estudar, ou melhor, retirar as particularidades sem as quais o fenômeno continua a manter a sua essência. Ao retirar-se aquilo sem o qual o objeto não é mais alcançado em sua essência, alcançamos o eidos. Convém ressaltar o alerta de Sousa e Giorgi (2010, p. 60): "A redução eidética, desempenhada pela variação livre imaginativa, não é realizada empiricamente, quer se trate de um objeto físico, de uma vivência psicológica ou de qualquer outro objeto não físico". Portanto, a essência do fenômeno é alcançada via o exercício do pensamento em que as perspectivas pelas quais o fenômeno pode ser percebido possam ser consideradas.

E por fim, a última etapa consiste em uma análise compreensiva em que se descreve a essência da descoberta, ou seja, essência da relação consciência e fenômeno. Trata-se de uma análise descritiva do fenômeno em busca das essências constitutivas de seu aparecer. Nessa etapa do método, cabe explicitar a dinâmica existencial do aparecimento do fenômeno. Como afirmam Sousa e Giorgi (2010, p. 65), "a análise fenomenológica implica em uma descrição dos fenômenos, tal como são visados pela consciência intencional".

Brice (1991), fenomenólogo norte-americano, estudioso da experiência dos enlutados, realizou uma pesquisa sobre a experiência do luto materno nas diferentes etapas do método empírico-fenomenológico: por meio da redução fenomenológica, suspendeu todas as teorias prévias acerca do tema, fossem elas oriundas das ciências naturais, fossem das teorias psicodinâmicas; em um exercício de variação imaginativa, buscou nos encontros com as mães as unidades de significado presentes em seus discursos: a experiência de um projeto interrompido; a impressão de que o filho pode chegar a qualquer momento; a sensação de amputação. E, por fim, alcançou a estrutura geral do fenômeno: o luto materno é um para sempre.

Nas experiências de luto, tal como aparecem em nossas práticas clínicas durante a pesquisa, a base metodológica se impõe com os seguintes elementos: 1. redução e suspensão de todas as verdades ditadas pela ciência acerca da morte e do luto por meio de teorias, manuais, compêndios, perfis e sinais, para assim podermos ver o fenômeno tal como ele se mostra a nós em sua complexidade e particularidades; 2 . análise eidética que ocorre por um exercício de variação livre imaginativa para alcançar as estruturas invariantes do objeto de estudo; 3. análise compreensiva e consequente descrição da estrutura geral do objeto.

\section{Resultados}

O psicólogo clínico, na perspectiva fenomenológico-existencial, sabe que a morte é indissociável da vida e, portanto, futuro de todos nós. Quanto ao luto, retiramo-lo da categoria do tempo aceitável para essa experiência, tal como podemos constatar no Manual diagnóstico e estatístico de transtornos mentais: DSM-5 (American Psychiatric Association [APA], 2014), de até doze meses para adultos e seis meses em crianças. 
E, ao não vermos mais o luto por meio dos manuais, passamos a vê-lo como a dor que o tempo ameniza, mas não cura. E por identificar essa dor do luto por um filho como algo da ordem de uma temporalidade eterna, como disse Brice (1991), e, ainda, como algo imensurável, é que acompanhamos a dor da mãe em silêncio. E para, nesse silêncio, podermos compreendê-la em seu desespero, uma vez que ela luta por algo que independe de sua força, de forma a que a mãe enlutada, ao se encontrar com a escuta atenta do psicoterapeuta, possa se sentir acolhida em sua dor.

Para encaminhar uma resposta à questão acerca do silêncio como algo da ordem da inutilidade, cabem alguns esclarecimentos: o silêncio acolhedor é algo que as pessoas em geral têm muita dificuldade em fazer. Elas quase que invariavelmente dão conselhos ou tentam fazer com que o enlutado se livre rapidamente daquela situação. Em investigação anterior com pais e mães enlutados (Franqueira, 2013, p. 93), pudemos acompanhar o quanto os enlutados ficam indignados com as tentativas de consolo, tais como: "Deus quis assim, vai passar, você tem outros filhos com quem você deve se preocupar" etc. O silêncio a que estamos nos referindo é daquele que não tenta apaziguar, não dá conselhos ou se utiliza de frases feitas. É o silêncio que acolhe o outro em sua dor, sem pensar se aquela experiência é patológica ou não, se precisa ser elaborada ou não. Esse silêncio não significa indiferença e nem mesmo desatenção, ao contrário, ele diz de um aguardar respeitoso do tempo do outro. Silêncio, paciência e serenidade consistem no exercício clínico em uma perspectiva fenomenológico-existencial (Feijoo, 2010). Assim, o clínico acompanha a experiência do enlutado e se aproxima do outro no modo como que ele articula sua experiência. E esse psicoterapeuta aguarda serena e pacientemente que na e pela angústia, tal como definida por Kierkegaard (1843/1968), como a realidade da liberdade como possibilidade para a possibilidade, o poder criativo possa acontecer. Para Kierkegaard (1843/1968), angústia abre-nos para a liberdade; e a liberdade abre a possibilidade de criação.

\section{Discussão}

Uma mulher de 50 anos procura atendimento clínico pelo fato de ter perdido seu filho de 12 anos, acometido pela Covid-19. Ela inicia a sessão em um relato no presente do indicativo, como se seu filho estivesse vivo:

A gente, como todo mundo, penso eu, está sem hora direito para dormir, então vou dormir entre três e quatro horas da manhã. Ele também dorme muito tarde, aí acabo ficando na cama até mais tarde, mesmo acordando, às vezes, continuo tentando dormir.

A psicoterapeuta permanece em silêncio - desse modo mostra-se atenta e acolhe aquilo que a mãe tem a dizer. A mãe enlutada continua: 
Doutora, eu estou melhor, mas às vezes parece que vou ficar louca, porque penso que na verdade não fui uma mãe boa. Porque me fiz procurar, me preocupar com coisas que talvez eu não tinha que me preocupar. Pensando bem com a razão, meu filho precisava de uma mãe ali presente, pois eu estava trabalhando e me preocupando com colégio e com a casa e não percebi o quanto ele precisou da mãe dele. Hoje vejo, é tarde e não tenho como corrigir essa dor que não tem volta. Isso é o que é na verdade. Mesmo revoltada, eu digo que acabei matando meu filho. Por isso, preciso ser punida, eu nem vou mais agradecer a Deus, todo dia, por mais um dia de vida para ver se ele me ouve logo e me leva para junto do meu filho. Ele me faz muita falta e precisou de mim, e eu não fui uma boa mãe porque boa mãe é aquela que a todo momento está ali. Eu não pude fazer isso, um filho não precisa de uma mãe que trabalhava o dia todo e só vê a mãe às 8h30, depois as 21 h55 ou 23 horas. Mãe que, às vezes, chega e ele está dormindo.

Nesse trecho, a mãe refere-se ao seu débito, culpabiliza-se pelo fato de não ter estado mais presente na vida do filho. Ressente-se por ter exigido que o menino estudasse. Arrepende-se de ter se dedicado à casa. Ela, muitas vezes, revolta-se com a condução da equipe médica e, ao mesmo tempo, considera que é a verdadeira culpada pelo que aconteceu. Passa a duvidar da existência de Deus e, ao mesmo tempo, diz que não vai ser mais grata a Ele porque quer morrer. A culpa, o ressentimento, a revolta e o desejo de morrer são temas a serem tratados na sessão, mas ainda é cedo. Nesse momento, todo o tempo é ofertado à mãe para que ela possa falar de tudo que Ihe vem à cabeça por diferentes motivos. O primeiro deles é que ela precisa falar e dificilmente há quem queira ouvir a voz da dor, da revolta, do ressentimento e, acima de tudo, da morte e do luto. Por isso, é preciso uma escuta atenta e paciente. $\mathrm{E}$, assim, continua o encontro.

Hoje eu estou vendo isso, sabe?, meu filho já estava precisando de mim, e eu não vi por ele estar todo cheio de energia. Meu bichinho já devia estar com isso já há um tempo. Eu nunca imaginei meu filho ficar com isso, pela minha ignorância. Assim que ele ficou internado, eu nem sabia falar infeç̧ão generalizada, para ver a minha burrice aonde chega. Então acho que nada vai mudar minha culpa e de uma coisa eu tenho certeza, não tenho mais vontade de continuar. Eu acabei sendo culpada pela morte do meu filho. Tenho que parar de culpar Deus, como fiz de início. E se existe mesmo um Deus no céu como falam as pessoas, eu não estou mais acreditando, porque é uma dor muito grande que nos é causada. Então, me pergunto: que Deus é esse que nos deixa perder alguém tão importante na nossa vida. Eu na verdade não estou conseguindo aceitar. Eu tenho certeza só de uma coisa: quero ir, sei que estou sendo egoísta, mas minha mente, meu coração quer ir embora, quero poder ver meu filho. Só não sei se alguém realmente vai para outro universo. Sei lá! Só eu morrendo é que vou 
saber. Sei que estou sendo egoísta, mas sei que, se existe mesmo esse Deus, que as pessoas tanto falam, Ele vai me ouvir, vou poder abraçar meu filho e pedir perdão.

Essa mãe enlutada mostra sua ambiguidade com relação à crença em Deus. Por um lado, quer acreditar que verá seu filho um dia, que poderá aliviar a sua culpa conseguindo o perdão do filho. Por outro lado, no relato anterior, ela mostrava revolta e indignação, como se tivesse sido traída por Deus. Agora percebe que, na verdade, ela não aceita a morte do filho. No relato anterior, ainda culpabilizava a equipe médica, neste último relato assume totalmente a sua culpa. Tudo isso se mostrava, mas ainda era cedo para que o psicoterapeuta falasse alguma coisa. O silêncio e a escuta atenta consistiam, nesse momento, na arte do bem perguntar. E a mãe continuava a falar de sua culpa, de seu débito, ou seja, de ações que agora ela acredita que deveria ter tido, mas não teve.

Hoje, além da saudade, eu me arrependo tanto, porque eu dei um valor ao estudo e a um quarto, que na verdade é coisa de gente sem noção. E eu sou assim: sem noção. Meu filho era uma criança, por isso ele precisava ser levado a médicos com frequência. Eu só levava quando ele sentia algo. Isso que eu fazia não era para ser assim. Estou me arrependendo tarde demais. Nossa! Me sinto um lixo, eu preciso pagar, preciso ser punida. Meu filho sofreu, minha vida passou por esse sofrimento dessa doença e, ainda, passou por essa doença maldita, desse vírus maldito, que talvez ele conseguisse sobreviver. Mas meu bichinho precisou, e o que fiz? O levei para esse lugar ruim, depois, para completar, teve que passar por esse hospital maldito que contaminou meu filho. Mas minha cabeça não está suportando. Eu me culpo, culpo o hospital. Preciso saber o resultado do UPA [unidade de pronto atendimento], apesar de eu ter certeza que foi no hospital que eu o levei. Mas posso também estar querendo me enganar. Quem garante que meu filho já não saiu daqui com esse vírus. Mesmo eu com muito cuidado, enchendo o saco dele, coitadinho. Eu preciso saber, vou tentar ver se um advogado me ajuda a saber o resultado do UPA. Talvez assim eu possa ver que não foi a infecção que o matou. E eu não ficar com essa certeza de que foi no hospital. Eu preciso saber isso, por mim e por meu filho. Preciso saber quem realmente foi responsável. Eu sei que sou culpada de não ter sido uma mãe presente. E a verdade, se ele já estava ou se foi contaminado no hospital, isso para mim é importante.

Agora, ela quer conhecer a verdade e quer lutar para saber onde afinal começou o desfecho trágico. Dessa forma, ela acredita que pode aliviar um pouco de sua culpa. Sem dúvida, nessa mãe aparece a dor da perda de seu filho, mas também o sofrimento que vem acompanhado pela culpa, pela indignação e pela revolta. O psicoterapeuta ouve a dor e acolhe aquele que está tomado por ela. Quanto ao sofrimento, cabe ao psicoterapeuta, por meio da 
arte do bem perguntar, demorar-se nele de modo a poder, pouco a pouco, deixar que ele se transforme, na medida em que o possível possa aparecer para a mãe em sofrimento. Mas ainda era cedo, era preciso escutar e calar, era preciso acolher o outro em sua dor e no seu sofrimento. Ainda o que se mostrava era o ter que contar, expressar sua culpa, sua revolta. Nesse momento, não importava saber sobre a condução da equipe médica a que a paciente se referia com tanta revolta. Isso consistiria em interrompê-la na expressão de seus afetos. Qualquer interrupção poderia soar para essa mãe como incompreensão, e, ainda, ao psicoterapeuta, na perspectiva fenomenológico-existencial, não cabe ser curioso (Feijoo, 2010). A curiosidade o afastaria do que é mais importante em uma relação psicoterapêutica: a continuidade da expressão dos afetos.

Meu filho sofreu, não consigo parar de pensar no meu filho, o rostinho dele conversando, respirando forçado. Coitadinho! Lindo da mãe, precisando de ajuda, e ajuda nenhuma resolveu, ninguém o ajudou nem o Deus do impossível, como as pessoas dizem. Porque eu até acreditava que sim, mas pedi tanto pelo meu filho e não fui ouvida. Se Ele gosta de castigar alguém, então esse foi o melhor castigo que Ele me proporcionou.

Outra vez aparece a ambiguidade: ao mesmo tempo que acredita que para Deus tudo é possível, decepciona-se. Mas como ainda é difícil acabar com essa crença, diz: "foi punição". Agora ela vê o Deus que castiga, pune, como presente no Primeiro Testamento. Também nesse trecho, ela se vê sozinha nessa luta e diz: "Ninguém o ajudou". E então começa a contar uma experiência passada em que fica muito claro para ela o abandono.

Também a velhice, por que ficamos dependente de todo mundo e não respondemos mais pelos nossos atos? Já fui cuidadora, eu brigava por eles porque algumas pessoas são tão egoístas que não têm respeito pelos idosos. Cansei de ver. Um patrão, uma vez, olhou na minha cara e disse que eu tinha que trabalhar numa ONG, porque eu brigava pelo idoso, eu chorava por ver como eles se tornam pessoas tão pouco importantes para algumas pessoas. Mas eu acabo me enxergando assim também. Hoje meu filho precisou de mais atenção, e eu fiz como essas pessoas, não dei a atenção que realmente meu filho precisou. Isso me dói porque agora é tarde para uma criança que era feliz e tinha uma vontade enorme de viver, tinha um lindo sorriso no rosto, menino maravilhoso! Eu hoje vi uma mãe que perdeu seu filhinho de um prédio. Ele caiu, coitadinho, mais uma mãe que sofre. Nossa! Que mundo perverso! Só sofrimento, ainda mais nós, sem condições financeiras, as crianças são obrigadas a viver só com o básico. Nossas crianças sofrem, não têm uma condição decente, aí acabam sofrendo as consequências. Eu estou tão assim, estou percebendo que o tratamento me deixa bem, mas, às vezes, eu me pego tão triste, me sentindo culpada, que só quero 
encontrar muito rápido com meu azedinho, ele precisa que eu peça perdão e quero mostrar para ele o quanto o amo e o quanto ele está me fazendo falta.

Essa mulher de 50 anos nunca havia ouvido falar em psicoterapia, do mesmo modo que nunca ouvira falar de infecção generalizada. Ela reconhece que falar com a psicoterapeuta a deixa bem, mas logo depois toda a dor volta na mesma intensidade que antes. Em todos os trechos apresentados, predomina a expressão de dor. E diante da dor que a domina, na arte do bem perguntar do psicoterapeuta, mostra-se oportuno (tempo Kairós) o silêncio.

Essa mãe mantém-se na experiência de tempo como presente do indicativo. Os relatos dela, que se apresentam como experiência passada, referem-se à culpa - ou seja, ao passado presente -, ao ressentimento. Para o futuro, essa mãe só vê a possibilidade da morte e com isso ela se designa como egoísta. É preciso, novamente, pacientemente, poder aguardar o momento oportuno, para que o passado se apresente como recordação - em que outras experiências possam aparecer para além das expressões de desleixo e pouca atenção com o filho. E, ainda, à medida que ela conseguir se libertar do passado lamentado, do presente opressor, o futuro poderá aparecer como possibilidade. Precisamos, ainda pacientemente, romper com os laços da ilusão. Essa mãe via-se invulnerável, e mesmo assistindo a tantas mortes de filhos, a tantas mortes causadas pela pandemia, acreditava de forma iludida que isso acontecia aos outros, a ela não.

Ao analisarmos os dados do encontro relatado aqui, vemos que para chegar a ele precisamos, primeiramente, compreender que todo fenômeno ao ser alcançado se dá em uma redução fenomenológica, e, para tanto, foi necessário suspender todas as teorias que se referem ao luto. Sejam elas oriunda do DSM-5 (APA, 2014), em que o luto é tomado a partir de sua duração temporal, seja das teorias psicanalíticas, psicológicas ou psiquiátricas.

Ao acompanharmos o relato da mãe em uma variação imaginativa, alcançamos reflexivamente os sentidos ou as unidades de significado presentes no relato: culpa, revolta, tristeza profunda, desejos de morrer, solidão, experiência de tempo alongado - eterno presente.

Em conclusão, uma análise compreensiva e a consequente descrição do fenômeno nos mostram que essa mãe enlutada, ao falar da indiferença do mundo, dá-se conta de que ela também foi indiferente ao filho. Volta a sua culpa. Logo, ela se lembra de outra mãe enlutada, solidariza-se com ela. Depois vem a revolta, agora dirigida às diferenças econômicas. E, por fim, fala da saudade, da falta - quer se encontrar de novo com ele. Portanto, culpa, solidariedade, revolta e saudade mostram o fenômeno do luto materno nos primeiros dias após a morte do filho. 


\section{Considerações finais}

Por fim, estudiosos da psicologia podem perguntar como se deu a elaboração do luto no encontro aqui apresentado. Cabe ressaltar que, na perspectiva fenomenológico-existencial, em psicoterapia não se trabalha com elaboração. Elaborar diz respeito a um psiquismo que de algum modo processa o acontecimento. Na perspectiva com a qual trabalhamos, em diálogo com Heidegger, prescindimos do psíquico (Feijoo, 2010) e, dessa forma, importa a experiência na qual a dor é insuperável.

A técnica utilizada não diz a uma ação com um fim antecipado. Na clínica fenomenológico-existencial, acompanhamos compreensivamente a experiência de dor do enlutado por meio de atitudes do clínico que são: a paciência, a serenidade e a arte do bem perguntar (Feijoo, 2020). Ressaltamos que o silêncio, como a atitude do psicoterapeuta que predominou no encontro aqui relatado, consiste em um manejo clínico em que compreensão, paciência e serenidade aparecem com toda força. 


\section{Referências}

American Psychiatric Association (APA). (2014). Manual diagnóstico e estatístico de transtornos mentais. DSM5. (M. I. C. Nascimento, trad.). Artes Médicas.

Azevedo, A. F., \& Pereira, M. A. (2013). O luto na clínica psicológica: Um olhar fenomenológico. Clínica \& Cultura, 2(2), 54-67. https://seer.ufs.br/index.php/clinicaecultura/article/view/1546

Boss, M. (1988). Angústia, culpa e libertação. ( $3^{\mathrm{a}}$ ed.). Livraria Duas Cidades.

Bowlby, J. (1980). Attachment and Loss. (vol. 3 Loss). Hogarth Press.

Brice, C. W. (1991). What forever means: An empirical existential-phenomenological investigation of maternal mourning. Journal of Phenomenological Psychology, 22(1), 16-38. https://doi. org/10.1163/156916291X00028

Comte-Sponville, A. (1997). Bom dia, angústia. Martins Fontes.

Esslinger, I. (2008). O impacto do suicídio na família. In M. J. Kovács \& I. Esslinger (Org.), Dilemas Éticos. (pp. 23-30). Loyola.

Feijoo, A. M. (2010). A escuta e a fala em psicoterapia: Uma proposta fenomenológico-existencial. IFEN.

Feijoo, A. M. (2011). A existência para além do sujeito: A crise da subjetividade e suas repercussões para a possibilidade de uma clínica psicológica com fundamentos fenomenológico-existenciais. VIAVERITA.

Feijoo, A. M. (2020). Instante, salto, epifania e transformação: Filosofia, literatura e psicologia clínica. Fhenomenology, Humanities and Sciences, 1(2), 339-348. https://phenomenology.com.br/index. php/phe/article/view/32

Feijoo, A. M. L. C. (2021). Situações de suicídio: Atuação do psicólogo junto a pais enlutados. Psicologia em Estudo, 26(1), 1-13, e44427. https://doi.org/10.4025/psicolestud.v26io.44427

Fogel, G. (2010). O homem doente do homem e a transfiguração da dor. Mauad.

Franqueira, A.M. (2013). Destruídas ou transformadas: O luto do filho adulto sob a ótica das mães. [Unpublished Master's Dissertation]. Pontifical Catholic University of Rio de Janeiro.

Freitas, J. L. (2013). Luto e fenomenologia: Uma proposta compreensiva. Revista da Abordagem Gestáltica - Phenomenological Studies, XIX(1), 97-105. http://pepsic.bvsalud.org/pdf/rag/v19n1/ v19n1a13.pdf

Freitas, J. L. (2018). Luto, pathos e clínica: uma leitura fenomenológica. Psicologia: USP, 29(1), 50-57. https://doi.org/10.1590/0103-656420160151

Freud, S. (1975). Standard Edition of the Complete Psychological Works. Hogarth.

Husserl, E. (2000). Ideias para uma fenomenologia pura e para uma filosofia fenomenológica. (Vol. III - La fenomenologia y los fundamentos de las ciencias). (Luis Gonzales, Trad.). UNAM.

Kierkegaard, S. (1968). O conceito de angústia. Hemus.

Kierkegaard, S. (2010). O desespero humano. Editora UNESP.

Kovács, M. J. (1992). Morte e Desenvolvimento Humano. Casa do Psicólogo.

Kubler-Ross, E. (1998). Sobre a morte e o morrer. (8 ed.). Martins Fontes.

Sousa, D., \& Giorgi, A. (2010). Método fenomenológico de investigação em psicologia. Fim do Século. 
EQUIPE EDITORIAL

\section{Editora-chefe}

Cristiane Silvestre de Paula

\section{Editores associados}

Alessandra Gotuzo Seabra

Ana Alexandra Caldas Osório

Luiz Renato Rodrigues Carreiro

Maria Cristina Triguero

Veloz Teixeira

\section{Editores de seção}

"Avaliação Psicológica"

Alexandre Serpa

André Luiz de Carvalho

Braule Pinto

Luiz Renato Rodrigues Carreiro

Vera Lúcia Esteves Mateus

"Psicologia e Educação"

Alessandra Gotuzo Seabra

Carlo Schmidt

Regina Basso Zanon
"Psicologia Social e Saúde das

Populações"

Enzo Banti Bissoli

Marina Xavier Carpena

"Psicologia Clínica"

Carolina Andrea Ziebold Jorquera

Julia Garcia Durand

Natalia Becker

\section{"Desenvolvimento Humano"}

Maria Cristina Triguero

Veloz Teixeira

Rosane Lowenthal

\section{Suporte técnico}

Maria Fernanda Liuti

Bento da Silva

Camila Fragoso Ribeiro
PRODUÇÃO EDITORIAL

Coordenação editorial

Ana Claudia de Mauro

Estagiários editoriais

Júlia Lins Reis

Élcio Carvalho

Pietro Menezes

Preparação de originais

Carlos Villarruel

\section{Revisão}

Vera Ayres

\section{Diagramação}

Acqua Estúdio Gráfico 